trabalho permitiu elucidar muito do que hoje se sabe sobre estrutura e reactividade de moléculas orgânicas e organometálicas em superfícies metálicas, e tem implicações industriais e ambientais: esclareceu o processo de adsorção e desadsorção dissociativa de hidrogénio em superfícies de monocristais de metais catalíticos como platina, paládio, níquel e ruténio, e a oxidação de monóxido de carbono em diversas superfícies. Em paralelo com as experiências de índole fundamental em substratos modelo, Ertl manteve interesse na catálise real. $\mathrm{O}$ seu trabalho sobre $\mathrm{O}$ mecanismo da reacção de formação de amónia a partir de hidrogénio e azoto, recorrendo a catalisadores à base de ferro e de ruténio, resultou

Este ano a Assembleia Geral (AG) da Associação Europeia de Ciências Químicas e Moleculares (EuCheMS) teve lugar em Frankfurt, nos dias $4 \mathrm{e}$ 5 de Outubro de 2007, a convite da GDCh (Sociedade Alemã de Química).

AAG contou com a presença de cerca de 70 pessoas, entre as quais representantes das diversas sociedades membros, os responsáveis pelas divisões e grupos de trabalho (GT) da EuCheMS, a Direcção e personalidades convidadas.

A iniciar a sessão, o Prof D. Jahn, Presidente da GDCh, deu as boas vindas aos presentes, no auditório de DECHEMA (Sociedade de Engenharia Química e Biotecnologia), referindo a actualidade e a urgência do trabalho das Sociedades de Química na construção da imagem dos químicos, e na captação de novos talentos. Referiu também que o trabalho e a colaboração internacional são, neste domínio, essenciais. Em seguida, o Presidente da EuCheMS agradeceu à GDCh e à DECHEMA a hospitalidade relativa a esta reunião. Deu as boas vindas a todos e em particular aos cinco representantes de Sociedades de Química Americanas, e ao Presidente da So- numa contribuição importante para a síntese da amónia pelo processo de Haber-Bosch, utilizado para produzir fertilizantes artificiais a partir do azoto atmosférico usando uma superfície de ferro como catalisador.

Publicou mais de 670 artigos em revistas com elevado impacto na comunidade científica, e, em colaboração com Helmut Knözinger, Ferdi Schüth e Jens Weitkamp, foi editor do Handbook of Heterogeneous Catalysis, uma enciclopédia de referência sobre catálise heterogénea em cinco volumes.

Gerhard Ertl orientou mais de 100 estudantes de doutoramento e inúmeros de pós-doutoramento, vindos de

\section{Assembleia Geral da EuCheMS}

ciedade Europeia de Física, convidados.

Entre as decisões tomadas nesta reunião realçam-se:

i) Eleição, por unanimidade, do Prof. Luís Oro, antigo Presidente da Real Sociedad Española de Química, para Presidente da EuCheMS;

ii) Integração da Sociedade Química Catalã como sociedade sócia da EuCheMS;

iii) Aprovação do Grupo de Trabalho em Química Orgânica bem como a sua passagem a Divisão, por cumprir o requisito mínimo de representantes de sociedades membros. O Prof Jay Siegel, responsável por esta iniciativa, fez uma curta apresentação, referindo que há 23 participantes, dos quais 16 puderam estar presentes na $1^{\text {a }}$ reunião em Zurique em Agosto. Apresentou o programa de trabalhos que incluirá diversos congressos e acções em prol de jovens cientistas, bem como intervenções no domínio da Ética;

iv) O GT de Química Inorgânica, de que é responsável o Prof. Katsaros, passou também a Divisão;

v) Criação de um GT em Química Verde e Sustentável; todo o mundo, muitos hoje reconhecidos no domínio da ciência de superfícies. É conhecida a recomendação que habitualmente fazia aos seus alunos: "Tentar sempre resolver cada problema até ao fim. É muito importante ser paciente!".

\section{Notas}

${ }^{1}$ George C. Schatz e Donna Minton, "Congratulations to Nobel Laureate Gerhard Ertl", mensagem da American Chemical Society, 18 de Outubro, 2007.

${ }^{2}$ Chemical \& Engineering News, 10 de Outubro, 2007

Laura llharco DEQB-IST

vi) Aprovação, por unanimidade, de uma declaração de compromisso de promoção do desenvolvimento sustentável;

vii) Aprovação, por unanimidade, do relatório de contas de 2006;

viii) Eleição, por proposta do Presidente da Assembleia Geral, dos representantes da Roménia (Corneliu Radu) e da Sociedade Flamenga de Química (Roger Dommisse) como revisores para as contas anuais da EuCheMS, cujas funções serão as de participar numa reunião em Londres, com o Tesoureiro, para reverem os elementos financeiros. As despesas de deslocação do tesoureiro e revisores, caso não possam ser pagas pelas sociedades membros, serão pagas pela EuCheMS;

ix) Aprovação, com duas abstenções, do orçamento de 2008, apresentado pelo signatário, na sua qualidade de tesoureiro. Foi decidido que as sociedades que não honraram os seus compromissos fossem prevenidas uma última vez de que se não os honrarem, será proposta à AG 2008 a sua expulsão.

x) Aprovação, por unanimidade, da minuta da acta da AG de 2006 que 
decorreu em Moscovo, e da minuta da acta da AG Extraordinária realizada em Bruxelas em Abril (essencialmente para admissão de duas novas sociedades, uma Espanhola e outra do Montenegro).

Durante esta reunião decorreram também actividades de vários grupos de trabalho. Pietro Tundo apresentou as conclusões do grupo A, sobre química sustentável, que reforçam a necessidade de formação em química e divulgação do desempenho dos químicos. Sobre as conclusões do segundo grupo, química e sociedade, o Prof. De Angelis referiu a necessidade de reforçar a imagem da química e dos químicos junto da sociedade, mesmo a partir das tenras idades na educação (10-12 anos), incluindo a preparação dos formadores que hoje em dia não têm a qualidade suficiente, e a necessidade de que a química seja considerada como a base de vida e não o exclusivo de unidades de transformação longínquas. Foi ainda referido que todos os anos deveria haver uma semana de química organizada pelas sociedades sócias durante a mesma semana em cada país. O grupo 3 que tratou das prioridades EuCheMS chegou a conclusões reportadas pelo Prof. W. Koch. A EuCheMS deve vir a tornar-se financeiramente forte, e por exemplo deve encontrar meios de receber verbas dos seus congressos. Outra prioridade é, à semelhança da conclusão do grupo anterior, contribuir para o reforço da imagem da química, incluindo a melhoria dos formadores. Em seguida Richard Pike reportou as conclusões do último grupo de trabalho, nas quais sobressai a necessidade de uniformizar pelo aumento de qualidade a preparação que as Universidades Europeias conferem aos seus graduados.

Nesta AG foram feitas ainda várias apresentações. Nomedamente:

i) Em primeiro lugar interveio a Presidente da American Chemical Society (ACS), Katie Hunt, que expôs com pormenor a prioridade actual da química sustentável na ACS, e o papel que entende que as Sociedades de Química devem assumir;

ii) Emmanuel Boudard da CCE falou sobre o desenvolvimento da ini- ciativa ERA, e o objectivo Europeu de conseguir assumir a liderança do conhecimento, referindo em pormenor as diversas novas possibilidades de desenvolvimento de carreiras em I\&D, ERAMORE, ERA LINK, VISA;

iii) Glen Vaughan, autor do 'Brussels News' que a EuCheMS tem vindo a publicar, falou sobre as prioridades e as necessidades de actuação em prol da química, junto das autoridades europeias;

iv) O presidente-Eleito da RSC, David Garner apresentou a ISE (Initiative for Science In Europe), explicando os seu objectivos e prioridades, bem como a participação da EuCheMS;

v) Por último interveio o Presidente da Sociedade Europeia de Física (www.eps.org), que apresentou essa sociedade e mencionou a colaboração com a EuCheMS. Falou também acerca da importância de assegurar uma representação em Bruxelas, dizendo que poderia eventualmente aprender com a EuCheMS mas referindo ligações ao Comissário. Falou também da ERA e da formação na Europa, que urge generalizar uniformizando esta última e dinamizando a primeira Referiu a necessidade de integrar melhor as instituições que financiam investigação nos estados membros, e que também a colaboração com a indústria está ainda aquém daquilo que seria razoável almejar, razão pela qual a sua Sociedade considera a sua incrementação uma prioridade. Referiu que seria desejável encontrar mecanismos de financiamento de organizações tais como a EPS e a EuCheMS. Seria necessário criar um repositório Europeu dos materiais provenientes de congressos. Terminou enaltecendo a colaboração com a EuCheMS para benefício mútuo, que urge formalizar, nomeadamente a possibilidade de alargar aos seus sócios a disponibilidade do Brussels News;

vi) Foi apresentado o $2^{\circ}$ Congresso Europeu de química, dos pontos de vista organizativo e científico: www.euchems-torino2008.it/site/torino.asp

vii) A GDCh fez uma breve apresentação sobre o estado dos trabalhos de preparação do $3^{\circ}$ Congresso Europeu de Química;

viii) Foram apresentadas ainda a CEFIC/Suschem, o programa
Euro-bachelor e o Euromaster financiado pela Comissão, e a actividade COST de Química foi apresentada em seguida por Dietrich Shinzler (CMST).

As apresentações referidas encontram-se disponíveis em http://www. euchems.org/GovernanceStructure/2 007EuCheMSGA.asp.

O Presidente informou a AG acerca dos resultados das reuniões da Comssião Executiva. Referiu em particular a revitalização da ProChemE (veja-se, por exemplo, http://www.rsc.org/Education/Qualifications/EurChem.asp), a condição e duração dos mandatos dos Membros da Comissão Executiva criação de um Standing Committee on Strategy and Finance, a qual foi aprovada por unanimidade.

Em seguida mencionou também a Criação do EuCheMS Networking Scheme, que estende os privilégios (p.ex. inscrição mais barata em Congressos) dos sócios aos das outras sociedades membros, de acordo com aquilo que já é praticado pelas sociedades italiana, alemã e inglesa.

No final, o Presidente agradeceu ao Prof. Naray Szabo, seu antecessor e deu as boas vindas ao Prof. Oro, e em seguida encerrou a sessão, agradecendo mais uma vez às sociedades que receberam esta $A G$ e em particular ao Prof. Koch, secretário-geral da GDCh.

O signatário dispõe de informação pormenorizada sobre a maior parte dos assuntos tratados, que poderá disponibilizar aos interessados que o contactem por correio electrónico.

José Empis

Representante da SPQ na EuCheMS e Tesoureiro da EuCheMS jempis@ist.utl.pt 